\title{
CONTRATOS REAIS E O PRINCÍPIO DO CONSENSUALISMO
}

\author{
Giselda Maria Fernandes Novaes Hironaka \\ Professora Doutora de Direito Civil e \\ Direito Agrário nos cursos de Graduação e \\ Pós-Graduação das Faculdades de Direito \\ da Universidade de São Paulo e Mackenzie.
}

Resumo: $O$ trabalho tem por meta levantar a distinção entre os contratos reais e os contratos consensuais, especialmente à luz do princípio do consensualismo, para indagar, conclusivamente, se a diferenciação se anula ou não, se convém mantê-la ou se a dispensa se impõe.

No desenvolvimento, primeiramente se persegue a fonte romana, com o exame dos contractus e a evoluçāo do direito contratual em Roma. Ingressa a indagação temática pela Idade Média e atinge a Idade Moderna, esta última marcada pelo abandono das formas rígidas, formando-se, o contrato, tão apenas pelo puro consenso. Levanta-se, em segundo lugar, a crítica à aplicação excessivamente ampla do princípio do consensualismo, a comprometer outros princípios revigorados, em sede do direito contratual, como o princípio da função social do contrato. Para fundamentar a crítica, num outro momento se faz a análise dos contratos reais em espécie - mútuo, comodate, depósito -, sempre buscando as formas de expressão do equivalente romano.

Enfim, levanta-se em conclusão opiniōes doutrinárias divergentes sobre a tese fundamental: a distinção entre contratos consensuais e contratos reais sobrevive? E, pelo exposto, conclui-se pela insuficiência de fundamentação dirigida à aboliçäo da distinção, corroborando posiçōes deixadas ao longo do estudo, tais como: o principio do consensualismo habita toda a modalidade contratual; está, pois, também, nos contratos reais, ainda que deles se diga só se aperfeiçoarem com a tradição da coisa. Sem esta, não há contrato nulo, pois sequer contrato há. Sem esta, estará o contrato real meramente a caminho de seu perfazimento; no entanto, já tangenciado pelo princípio do consensualismo.

\begin{abstract}
The purpose of this paper is to make a distinction between real contracts and consensual contracts, especially in the light of the consent principle, in order to question, conclusively, whether the differentiation is void, should be maintained or should be dispensed with.

In the development of this paper, first the Roman source is explored, through the examination of the "contracts" and the evolution of Contractual Law in Rome. The thematic questioning then enters into the Middle Ages and reaches the Modern Age, the latter period marked by the abandonment of rigid forms, the contract being completed by mere consent.
\end{abstract}


Secondly, a criticism is raised concerning the excessively broad application of the consent principle, witch impairs other revigorated principles found in Contract Law such as the principle of the social function of the contract.

In support of the criticism, an analysis of real contracts in specie is later made loan, commodatum, deposit, always seeking forms of expression for the Roman equivalents.

In conclusion, divergent doctrinary opinions on the fundamental thesis are outlined: does the distinction between consensual and real contracts still subsist? And, in view of the foregoing it is concluded that there are insufficient grounds for abolishing the distinction, ratifying positions assumed in the course of the study such as the following. the consent principle is present in all types of contracts; it is, therefore, also found in real contracts, in spite of the fact that it is said of the latter that they are only completed with the delivery of the thing. Without such delivery, there is no void contract, for a contract does not even exist. Without delivery, the real contract will merely be in the process of being completed, although already marked by the consent principle.

Unitermos: Contratos; Contratos Reais; Contratos Consensuais; Consensualismo; Mútuo; Comodato; Depósito.

\section{Retorno às origens romanas e evolução.}

O direito romano conheceu o contractus sob uma visão muito mais restrita que esta do direito moderno. Reconheceu o seu fundamento no ajuste das vontades das partes contratantes, gerador do acordo que, na conformidade da ordem jurídica, fez exsurgir o ato jurídico bilateral.

Só eram considerados contractus os acordos de vontade que se destinassem a criar relaçōes jurídicas obrigacionais, e não outras. No entanto, convém ressaltar, as obrigações não se apresentavam como consequiência mera do simples acordo. Tanto é verdade que nuda pactio obligationem non parit, advertia já o Digesto (D.14.7.4).

Assim, o romano necessitou de um elemento a mais, além do simples acordo, para tornar possível a existência da obligatio. Este liame jurídico pôde emergir no momento em que se somou ao acordo a causa civilis, ou seja, uma exteriorização da forma, sem a qual, não seria possível se falar em contractus. E o vinculum juris que consistia na obligatio dependeu, então, além do consensu, também de atos solenes tais quais o nexam e a stipulatio.

Apenas assim, o credor de tal contractus tinha à sua disposição uma actio derivada do direito quiritário e que lhe permitia perseguir, em juízo, a prestação, constrangendo o devedor a prestá-la.

Desta forma, é possivel, desde já, compreender a figura paralela ao contractus, que era o pactum e demonstrar a diferença existente entre elas, ainda que a partir da inferência de que, ambas, derivam da expressão genérica conventio. O pactum, que também era acordo de vontade lícito, não gerava obrigações e não 
permitia, como na outra fórmula ocorria, a rem persequendi in iudicio, isto é, não se lhe reconhecia e nem se lhe colocava à disposição, a actio.

Muitas modificações sofreu o direito contratual em Roma, durante sua evolução, de tal sorte que houve um alargamento do continente dos contratos, dos acordos de vontade aos quais a ordem jurídica concede a eficácia de gerar obrigações.

O direito romano primitivo apenas conheceu os contratos formais, cujas categorias eram verbis e litteris revelando cada uma, respectivamente, o seu elemento formal, ou pelo uso das palavras sacramentais, ou pela inscrição no livro contábil.

Os dois contratos formais que primeiro Roma conheceu foram o nexum e a stipulatio, com sua troca de expressões ou fórmulas obrigatórias. Assim, por exemplo, o nexam mostrava-se como um tipo de empréstimo realizado per aes et libram, isto é, sob um sério ritual, com fórmulas obrigatórias, uma balança, certos atos simbólicos e testemunhas, tudo com a finalidade de lhe ser atribuída eficácia. $\mathrm{E}$, recorde-se, no direito romano, a obrigação assim tão simbolicamente assumida - e como todas, até a promulgação da Lex Poetelia Papiria, no IV séc. -, e dado o caráter personalíssimo da obligatio, sujeitava o próprio corpo do devedor à execução daquela. Já a stipulatio, através do uso exclusivo da forma verbal spondere, tanto para a pergunta quanto para a resposta que se desse ao credor, revelava-se como a promessa solene de certa prestação.

Em época posterior, já à luz do direito clássico, o direito romano introduriu os contratos escritos, apesar da verdadeira aversão que tinham os romanos por tais fórmulas. $O$ formalismo romano que até então realizou-se sempre de modo público e verbal (os contratos verbis), passou a revelar-se através da inscrição de seus atos e solenidades no livro contábil do credor, o codex accepti et expensi, dando lugar aos contratos litteris.

Durante o perîodo clássico, observe-se, então, predominou ainda o princípio do formalismo, onde o elemento objetivo - forma ou datio rei - é que permitia exsurgisse a obligatio e sua força vinculante. Os contratos litteris, paulatinamente foram caindo em desuso e os verbis foram se amenizando e o formalismo foi sendo gradativamente dispensado.

No direito justinianeu, contrariamente ao que se verificou nos períodos primitivo e clássico, os juristas bizantinos visualizaram no acordo de vontades o verdadeiro pressuposto da formação e existência de um contractus. Nascia o princípio do consensualismo, com o afastamento exagerado da forma e com uma maior atenção à manifestação da vontade das partes.

Com isto, ultrapassa-se a fase romana que concebeu tão apenas um número de tipos contratuais, embora todos compatíveis com o contrato típico. Até mesmo o pactum aproveitou-se da transigência daquele rigorismo e da aplicação da idéia consensualista, de tal sorte que a ele, pactum, o pretor concedeu a actio in factum.

Assim, marcou-se a Idade Média pela abolição das rígidas formalidades e a simples referência de que os ritos haviam sido observados, passou a valer tanto quanto efetivamente realizá-los. 
E a Idade Moderna apresentou o contractus qui solo consensu perficitur, isto é, o contrato originando-se, tendo por nascedouro e perfazimento, apenas o consenso puro dos contratantes.

A este respeito escreveu Caio Mário da Silva Pereira (Instituiçōes, vol. III, p. 20): "Retomou uma velha parêmia, pacta sunt servanda, não apenas para dizer que os contratos devem ser cumpridos (princípio da força obrigatória), mas para generalizar que qualquer ajuste, como expressão do acordo de vontade das partes, tem igual força cogente".

O Direito canônico marcou sua contribuição nesta etapa evolutiva quando equiparou o descumprimento do avençado à mentira, e elevando-o à categoria de peccatum, já que a palavra dada e o dever de fielmente mantê-la, revelavam a idéia de que o consenso a tudo supera e a tudo se sobrepõe.

A mesma linha de raciocínio canonista adotaram-na jusnaturalistas do porte de Pufendorf (cf. Orlando Gomes, Contratos, p. 6), "para quem o contrato é um acordo de vontades, expresso ou tácito, que encerra compromisso a ser honrado sobre a base do dever de veracidade, que é o direito natural".

Modernamente, contudo, o princípio do consensualismo vem sendo vítima do mesmo "mal" que o princípio do formalismo, seu antecessor na história contratual: sua aplicação excessivamente ampla acabou por furtar-lhe as conveniências, com prejuízo para a segurança do contrato e dos próprios contratantes, com certa desatenção ao próprio princípio, hodiernamente consagrado, da função social do contrato, e com certo alheamento às modernas doutrinas que defendem os limites' à liberdade contratual.

\section{Os contratos reais antepostos aos contratos consensuais.}

Roma consagrou, além das modalidades verbais e literais, contratos reais e, depois, contratos consensuais.

Relativamente aos contratos reais, assim como os solenes, os romanos não os consideraram de modo a excepcionar o princípio do consensualismo.

Hodiernamente - raciocínio paralelo -, a própria distinção classificatória entre os contratos reais e os contratos consensuais, não aniquila o velho princípio do consensualismo.

No passado romano, os contratos reais surgiram, primeiro, através de um novo tipo de empréstimo, muito simples porque dispensava o rigor das fórmulas e simbolismo, e diferente porque se aperfeiçoava com a tão-apenas entrega da coisa ao devedor. Era esta entrega a traditio, que se apresentava (e não o consenso) como o elemento gerador da obligatio, de tal modo que só a partir de então é que o devedor encontrava-se obrigado à devolução.

Diz-se, assim, que os contratos reais são os que exigem, para o seu perfazimento, além do acordo de vontades, ainda a efetiva entrega da coisa.

Gaio apenas incluiu, nas Institutas (Inst. III, 90-91), esta espécie de empréstimo, cuja entrega da coisa emprestada fazia surgir, para o accipiens, a obrigação de restituí-la, sendo certo que referida entrega transferida (do tradens 
para o accipiens) não só a posse senão também a propriedade. Esta modalidae contemplada por Gaio denominava-se mutuum.

Mais tarde, o Aureonum Libiri - que se diz ser de Gaio ou se diz ser mera paráfrase às suas Institutas pelos jurisconsultos pós-clássicos -, admitiu mais três modalidades, todas com a mesma característica, qual seja, a de devolver a coisa entregue, oportunamente, ao tradens. Assim, encontraram-se, então, elencados o mutuum, o depositum, o commodatum e o contractus pignoraticius.

As Institutas de Justiniano (III, 14), contemplaram estas mesmas quatro espécies mencionadas. E desta época do direito justinianeu, também, o aparecimento de outras formas contratuais, revelando categoria em apartado, e que, pelo fato de não se encaixarem nas fórmulas típicas tradicionais, foram chamados, já desde os bizantinos, de contractus innominati.

Convém ressaltar apenas, por curioso, que entre o vasto elenco compreendido em tal categoria especial, destacou-se o contrato conhecido como permutatio, cuja execução consistia na traditio rem pro re, objetivando a entrega de uma coisa por outra e por isso distinguindo-se da emptio venditio. Há noticia historica de sua inclusão entre os contratos reais, à época de Justiniano.

Todavia, a grande novidade da inclusão das novas modalidades contratuais já mencionadas depositum, commodatum e contractus pignoraticius -, nas Institutas de Justiniano foi exatamente o fato de se estar permitindo que a restituição deixasse de ser, obrigatoriamente, do equivalente, podendo-se restituir a própria coisa.

Em momento histórico posterior, já às portas da era cristã, os romanos ampliaram, ainda, o horizonte contratual para permitir o conhecimento de outra categoria, distinta das anteriores, que contemplou modalidades nas quais o acordo de vontades era suficiente à perfeição do contrato. Eram os contratos consensuais, os que se formavam solo consensu. Thomas Marky (Contrato (Direito Romano), in Enc. Saraiva do Direito, v. 19, ps. 146-154), enumera os seguintes: emptio venditio, locatio conductio, societas, mandatum, pacta e, ainda, a doação.

3. Os contratos reais em espécie (mútuo, comodato e depósito).

\section{a. Mútuo (mutuum).}

Constitui, como o comodato, espécie de empréstimo, e, se deste último se diz ser empréstimo de uso, pelo fato de seu objeto ser infungível, daquele (do mútuo) se diz ser empréstimo de consumo, exatamente porque é fungível o seu objeto.

Seu conceito legal vem consagrado no art. 1.256 do CC, segundo o qual "mútuo é o empréstimo de coisas fungíveis", e sua sede legal mais próxima que a origem romana já examinada, repousa nas Ordenaçōes Filipinas (IV, 50, pr.), cujo texto, cf. Limongi França (Instituiçōes, p. 789), é o seguinte: "Toda a pessoa, que emprestar a outra cousa alguma, que consiste em número, peso, ou medida, como o dinheiro, vinho, azeite, trigo ou qualquer outro legume, tanto que se recebe a tal cousa emprestada, fica a risco daquele que a recebeu; porque pela entrega ficou 
própria, e fica sempre obrigado a pagar o gênero, que não podia perecer, que é outro tal dinheiro, trigo, vinho ou azeite ou outro legume".

De pronto, infere-se que a propriedade da coisa mutuada, isto é, o domínio do objeto do mútuo transfere-se à pessoa do mutuário (accipiens). $\mathrm{O}$ mutuante (mutuo dans) ao realizar a traditio, e porque se trata de res nec mancipi o objeto fungivel do contrato, estará, simultaneamente, entregando o domínio da coisa. E, como res perit domino, por conta do mutuário correrão todos os riscos, desde então, segundo a regra do art. 1.257 do CC.

O mútuo é contrato real, unilateral, gratuito e não solene.

Efetivamente é um contrato real, como vimos, pois apenas se perfaz com a entrega da coisa. Caso a entrega não se realize, não se poderá falar em inexecução contratual, já que tal ato não pertence ao momento da execução, mas ao momento da formação do mútuo. Também não há que se falar na possibilidade de ser nulo o contrato carente da traditio. Sequer há contrato, porque se falar em nulidade? E se não há contrato, não se fale também em efeitos.

A respeito, límpida e conclusiva é a lição de José de Oliveira Ascenção (Contrato Real, in Enciclopédia Saraiva do Direito, vol. 20, p. 92-96): "Se há acordo, mas não há entrega, há um trecho do contrato previsto por lei, mas não se realizou ainda toda a facti species. Isto nada tem de nulo: por isso, logo que se der a traditio o contrato está perfeito. Antes não: não produz efeitos, mas simplesmente porque não há ainda contrato. Nada impõe que o acordo e a traditio sejam simultâneos, de maneira a taxar de nulos os acordos que não foram acompanhados daquela".

Da sua própria realidade se aduz ser contrato de caráter unilateral, já que, após o seu perfazimento, nenhuma outra obrigação remanesce ao mutuo dans, senão apenas remanesce obrigação ao accipiens que é a de restituir o objeto emprestado.

Quanto à gratuidade, cumpre observar que se ela é da natureza do mútuo, não significa que ela seja da essência de tal contrato. Da natureza, sim, pois, a princípio concebeu-se tal espécie de empréstimo para regular os casos de espontâneo auxilio que alguém presta aos que the são caros, quer o sejam pelos laços sanguíneos, quer pelos laços do afeto.

Contudo, em nossos dias, como enfatizam os tratadistas, raramente encontramos o mútuo despido de um caráter especulativo.

A presunção de gratuidade foi superada pela realidade dos tempos, de tal sorte que, hoje, ela é mesmo inconcebível. Aliás, o direito romano já havia considerado a possibilidade de pagamento de juros no mútuo (stipulatio usurae e foenus), com a XII Táb. especulando de 8 a $10 \%$ a taxa de juros ao ano. Em fins da República, este percentual elevou-se para $12 \%$ ao ano, e Justiniano apresentou rigorosa tabela a respeito da onerosidade dos empréstimos. Entre nós, ao tempo da promulgação do Código Civil, o legislador não cuidou de prefixar os juros, deixando à livre resolução das partes esta fixação do percentual. Contudo, a Lei de Usura, de 1933, veio alterar tal situação, realizando a estipulação em $12 \%$ ao ano. A fixação de juros depende de claúsula expressa (art. 1.262 do CC).

Ainda com vistas ao aspecto da onerosidade do mútuo, como sendo a compensação pela utilização dos bens alheios, vale mencionar o chamado mútuo mercantil, assim considerado pelo C. Com., art. 247, se a coisa emprestada for 
considerada gênero comercial ou destinada a uso comercial, e mais, sendo, pelo menos o mutuário, comerciante. Este, que é o mútuo mercantil, ao contrário do mútuo civil, é considerado normalmente oneroso, conforme resuita do disposto no art. 248 do C.Com. O direito comercial, ainda em tal sede, nos apresenta outras figuras assemelhadas ao mútuo oneroso, tais como a abertura de crédito ou a promessa de mútuo. Arnold Wald (Obrigaçōes e Contratos, p. 288) assegura que "ao contrário do mútuo, a abertura de crédito é contrato consensual". Em seguida, refere-se ao contrato de conta corrente, "considerado pela doutrina como 'um mútuo de natureza especial'..." Interessantíssimo trabalho, a este respeito, é o parecer dado por Álvaro Villaça Azevedo à consulta que lhe fez a Caixa Econômica do Estado de São Paulo SA, CEESP, afirmando a natureza real do contrato de conta corrente (v. Direito Privado - 2, p. 113-125).

Por fim, quanto à forma, o contrato de mútuo é não-solene, isto é, não há previsão legal de forma obrigatória. No entanto, e face à disposição do art. 141 do CC, a prova testemunhal só é admitida nos contratos cujo valor não passe de NCz\$ 0,01 , razão pela qual é de bom alvitre ultimar-se por escrito este e todos os demais contratos ditos não-solenes.

E estas são as principais características deste contrato de mútuo que Alexandre Correia e Gaetano Sciascia (Manual de Direito Romano) definiram como o contrato real, unilateral e gratuito, em virtude do qual uma parte (mutuo dans) transfere a outra (mutuo accipiens), a propriedade duma determinada quantia de dinheiro ou de coisas fungíveis, com a obrigação de o mutuário restituir ao mutuante uma quantidade igual de coisas (tantundem) do mesmo gênero e qualidade.

Por último, observe-se a regra do art. 1.259 do CC, segundo a qual o mútuo feito a menor, sem autorização de quem de direito, não poderá ser reavido e o mutante não poderá exigir a restituição sequer dos eventuais fiadores ou abonadores.

Tal disposição não é nova no sistema positivo privado, mas, ao contrário, remonta aos Senatusconsultus Macedoniano que não conferia ação ao credor de menor, filius familiae, que houvesse daquele tomado algo por empréstimo.

As Ordenações do Reino (Liv. IV, Tít. 50, *2.) repetiram a mesma regra mandando "que o que emprestar a algum filho, que tiver debaixo do poder de seu pai, quer seja varão, quer fêmea, perca o direito de o pedir assim a seu pai, como a ele, posto que os ditos filhosfamilias, a que se fez o dito empréstimo saiam do poder de seus pais por morte, casamento, ou emancipação. E da mesma maneira não se poderá pedir aos fiadores, que por eles fiarami".

Entre nós, cessa a restrição do art. 1.259 do $\mathrm{CC}$, conforme dispõe o seguinte artigo, se o representante do menor ratificar o empréstimo (inc. I), ou se o menor, dada a ausência do autorizador, se viu na necessidade de emprestar para os seus alimentos habituais (inc. II) ou, ainda, se o menor possuísse bens elencados na categoria dos do art. 391, П, do CC, isto é, aqueles adquiridos pelo próprio menor em serviço militar, ou provenientes do magistério ou de qualquer outra função pública. 
Que não reste sem observação contudo, na esteira do ensino de Washington de Barros Monteiro (Obrigações, Parte 2, p. 241) que o dispositivo referido é, na verdade, ocioso, já que o menor se torna capaz através dos fatos indicados pelo CC, no artigo 391, I.

\section{b. Comodato (commodatum).}

Segundo Alexandre Correia e Gaetano Sciascia, comodato é "o contrato real, unilateral, gratuito, em virtude do qual uma pessoa (tradens) entrega uma coisa corpórea não-consumível a outra (accipiens) para que use dela e a restitua ao comodante".

Trata-se de cessão gratuita da utilização do bem (uso e gozo), através do qual o comodante presta um favor ao comodatário, e este fato é o determinante da responsabilidade deste último, o devedor. Sua obrigação será a de restituir a própria coisa recebida (eadem res), depois de usá-la conforme restou estabelecido no contrato.

O objeto do comodato, assim, deve compor, em si, as qualidades de infungivel e, mais, a de inconsumível. Caso simplesmente fosse fungível a coisa dada em comodato, poderia ela ser substituída no momento da restituição e esta, então, se revelaria como obligatio tantundem, imprópria da espécie contratual em exame.

Mas não apenas infungível deve ser a coisa, senão também inconsumível, pois, se consumível, a sua destruição pelo uso impediria a restituição na mesma individualidade (obligatio eadem res), o que, de resto, descaracterizaria a possibilidade de ser comodato o contrato.

Entretanto, excepcionalmente, o comodato poderá recair sobre coisa consumível e até mesmo sobre coisa fungível, ou, ainda, sobre coisas que, ao mesmo tempo, apresentem-se como consumível e inconsumíveis. Para que a exceção ocorra, urge que os contratantes atribuam, intencional e convencionalmente, a tais coisas, o caráter de infungibilidade e o de inconsumibilidade, sempre no claro propósito de que não venham elas a serem consumidas pelo uso convencionado no contrato.

Diz-se que o comodato é empréstimo de uso. Seu caráter unilateral emerge do fato de que, após a entrega da coisa pelo comodante ao comodatário, exclusivo momento de aperfeiçoamento de tal contrato, seus efeitos exsurgem apenas, desde então, o momento da sua existência própria. Tais efeitos revelam a uniteralidade, já que a única obrigação que remanesce, ao depois do ingresso do contrato nos planos de existência e eficácia, é a obrigação que tem o comodatário de restituir a coisa emprestada.

O uso da coisa, pelo comodatário, obriga-se sob determinadas regras, quais sejam, deve ser um uso normal, deve atentar para a finalidade imposta pelo contrato, deve ser um uso conservacionista da coisa e o seu beneficiário deve exercer esta utilização sobre a coisa como se ela fosse sua.

Por outro lado, evidentemente, o comodante deverá facilitar o uso da coisa por ele emprestada gratuitamente, permitindo que o comodatário dela se utilize pelo prazo estabelecido no contrato, ou se tal prazo for indeterminado, que dela se utilize pelo tempo necessário ao atendimento da finalidade do comodato, consoante a regra do art. 1.250 do CC. Concilia-se, assim, em harmonia, o direito que tem o 
comodante de reclamar a coisa a qualquer tempo, se o contrato for por prazo indeterminado, com o dever que a ele compete, também, de conceder o mínimo de prazo necessário ao comodatário, para que ele leve a cabo a intenção que moveu os contratantes no momento da gênese do comodato.

Reserve-se, contudo, a idéia de que tal modalidade contratual é sempre temporária, pois ainda que indeterminado o prazo de sua duração, ele será certamente, determinável. Não reconhecer a temporariedade do comodato seria confundi-lo com a doação.

Como contrato real que é e conforme tudo o quanto já restou anteriormente dito , sua própria existência depende da traditio. Antes dela, não há comodato, não há contrato, não se geram os efeitos.

Quanto à forma, caracteriza-se pelo fato de ser não-solene, como o é, igualmente, o mútuo. Advirta-se aqui, como lá, que apesar da não obrigatoriedade de forma, posto que não prescrito pelo ordenamento, é medida de segurança realizá-lo por escrito, pois que, assim, prova-se por si mesmo e não sucumbe ao disposto no art. 141 do CC.

Outras duas importantes características do comodato são mesmo a sua não sujeição a qualquer tipo de remuneração, sob pena de converter-se em locação; portanto, não se excepciona a sua gratuidade como pode ocorrer no mútuo. E, também, diferentemente daquela outra modalidade, o comodato não transfere 0 domínio da coisa àquele que a tomou emprestada.

A obrigação do comodatário, que é obrigação essencial, traduz-se, conforme visto, na restituição da coisa. $\mathrm{O}$ art. 1.252 do $\mathrm{CC}$, contudo, adverte que se converterá o comodato em locação se o comodatário incorrer em mora no cumprimentơ da sua obrigação de restituir a coisa. Sofrerá a sanção de pagar aluguéis durante o tempo do atraso em restituí-la, além de responder pelas perdas decorrentes da deterioração, quando da devolução.

Por outro lado, e se ainda dentro do prazo convencionado não constituído em mora, portanto, o comodatário -, se a coisa a ser restituída se perder, então antes da tradição, sem culpa do comodatário, sofrerá a perda o comodante, pois res perit domino, tudo conforme a regra do art. 869 do CC.

\section{c. Depósito (depositum).}

O conceito é legal, conforme o art. 1.265 do CC, esclarece que "pelo contrato de depósito recebe o depositário um objeto móvel, para guardar, até que o depositante o reclame".

É, afinal, "o contrato real, unilateral, em virtude do qual o depositante (tradens) faz a entrega de uma coisa corpórea móvel ao depositário (accipiens) que se obriga a conservá-la e a restituí-la a pedido do depositante", segundo Alexandre Correia e Gaetano Sciascia.

A obrigação do depositário - e que revela a unilateralidade do contrato consiste em guardar a coisa, conservá-la e, afinal, restituí-la, no estado exato em que a recebeu. De pronto, infere-se a proibição de uso da coisa, nesta modalidade contratual, posto que o depositário apenas a detém e o uso irregular se afigura como ilícito (furtum usus), conforme a disposição proibitiva do art. 1.275 do CC. A 
diferença fundamental entre o depósito e o comodato tem sede exatamente aqui: caso ocorra o uso da coisa, o depósito descaracteriza-se, ensejando o aparecimento do comodato. Regra perfeita sobre este assunto, a tem o CC espanhol, cujo art. 1.768, I, determina que a permissão dada ao depositário para usar a coisa depositada converte o depósito em comodato.

Como os contratos anteriormente examinados (mútuo e comodato), o depósito é um contrato real, pois que sua existência depende exclusivamente da tradição da coisa depositada. Não a recebendo o depositário, não se perfaz o contrato e não produz efeito algum.

É também, e em princípio, um contrato gratuito, já que o depositário está prestando um favor ao depositante de guardar e zelar pelos seus bens móveis, abstendo-se de usá-los e restituindo-os na ocasião ajustada. No entanto, verifique-se, a segunda parte do parágrafo único do art. 1.265 do CC admite que as partes podem estipular a gratificação ou remuneração do depositário. Tal fixação compensatória não desvirtua o contrato de depósito; poder-se-ia dizer que o depósito caracterizase, em regra, pela gratuidade e, excepcionalmente, pela onerosidade. Sob a luz do direito comercial, o depósito dito mercantil é sempre oneroso e, apenas como rara exceção, poderá vir de se apresentar como gratuito (artigo 282, Código Comercial).

O depósito recai, conforme o já mencionado art. 1.265 do CC, sobre bens móveis. Lembra Orlando Gomes (Contratos, p. 403) que "a principal razão para excluir os bens móveis é que sua guarda exige atos de administração incompatíveis com a função econômico-social do contrato. Seria assim" - prossegue o jurista - "um contrato de guarda, vizinho do depósito. A tendência é, no entanto, para admitir o depósito de imóveis, já permitido no seqüestro".

Em vários pontos o depósito afasta-se do seqüestro: aquele recai sobre coisas móveis, este recai sobre coisas móveis ou imóveis, mas sempre litigiosas; o depósito recai sobre bens que se sabe a quem pertençam, no seqüestro, o mesmo não acontece; o depósito é, em regra, gratuito e, excepcionalmente, oneroso; no seqüestro, o depositário não pode devolver a coisa antes que deixe de ser litigiosa, no depósito, ele poderá restituí-la antes de findo o prazo de duração do contrato.

Difere também o depósito do mandato, mormente porque, como bem explica Washington de Barros Monteiro, o detentor da coisa, no mandato, posiciona-se de modo ativo, realizando comissivamente o encargo de dar à coisa recebida uma certa aplicação, um certo destino; este mesmo detentor, no depósito, terá uma atitude passiva, que se circunscreve à incumbência de guardar.

Sob este prisma, não seria tarefa árdua compreender a natureza jurídica do depósito bancário, um misto de depósito, de mandato e mesmo de locação, conforme opina Álvaro Villaça Azevedo (a respeito, v. Depósito bancário, Sérgio Carlos Covello, in Enciclopédia Saraiva do Direito, v. 23, ps. 390-394).

Se, por acaso, a coisa objeto do depósito possuir a qualidade de fungível, é provável que a utilize o depositário, salvo convenção em contrário. Esta utilização, por assim dizer, fere a natureza mesma do depósito, pois que, além da esdrúxula ocorrência do uso, a restituição não se dará por :eadem res, mas o depositário realizará a substituição (tantundem) por outra coisa da mesma espécie, qualidade e quantidade, regendo-se a execução, pelas regras do mútuo. A circunstância é 
previsível pelo sistema positivo e o art. 1.280 do CC nos dá notícia desta espécie que é o depósito irregular ou depósito impróprio.

As especies de depósito reconhecidas pela legislação são o depósito voluntário e o depósito necessário.

Depósito voluntário - conceitua Orlando Gomes (Contratos, p. 404) - "ह́ o que se faz espontaneamente, mediante contrato entre os interessados". Deriva assim, da disposição livre das vontades, e traduz especialmente a faculdade que tem o depositante de escolher o depositário. Por isto, diz-se que esta espécie se realiza intuitu personae.

Já o depósito necessário, "é o que se realiza no desempenho de obrigação imposta por lei (depósito legal), ou quando se efetua por ocasião de alguma calamidade pública, como incêndio, inundação, naufrágio ou saque (CC, art. 1.282), o qual recebe a denominação tradicional de depósito miserável (depositum miserable), com as características de urgência e da escolha não voluntária do depositário", conforme a lição de Caio Mário da Silva Pereira (Instituições, III, p. 316) remetendo aos anteriores ensinamentos de Cunha Gonçalves (Dos Contratos em Especial, n. 105).

Por fim, convém tratar deste que é o mais singular traço do contrato do depósito, que é a prisão civil do depositário remisso, circunstância esta revestida de peculiaridade, vez que traduz a execução à regra de que ninguém pode ser preso por - dívida. "Resquício da prática odiosa da prisão por dívida", no dizer de Orlando Gomes (Contratos, p. 409), a tendência moderna é a de baní-la do contexto do direito civil, tendência esta que vem se mostrando quer pela preocupação dos juristas de rejeitá-la, quer pelo fato de que sua decretação tem sido mais e mais dificultada pelos nossos julgadores.

Submete-se à sanção mencionada o depositário infiel, isto é, aquele a quem foram confiados bens ou valores para guardar e conservar e que se nega a restituílos, mesmo em face do mandado judicial. O regime jurídico autorizante da circunstância de prisão civil por dívida é, a nível constitucional, o disposto no artigo 5., LXVII, da Constituição Federal de 1988 e, a nível instrumental, os arts. 901-906 do Código de Processo Civil.

4. Conclusōes: classificação dos contratos, em reais e consensuais, em face do princípio do consensualismo, hoje.

Por todos os aspectos até então apreciados, talvez resulte a compreensão de que os contratos reais quoad constitutionem são aqueles que só se perfazem com a tradição da coìsa.

$E$ É fato que não se os deve confundir com os contratos reais quoad effectum, já que aqueles quoad constitutionem não têm efeitos reais e estes, quoad effectum, não exigem, para seu perfazimento, a tradição da coisa, embora gerem efeitos reais.

Nestes contratos reais (quoad constitutionem), só a vontade é impotente para formá-los, pois a traditio, como se sabe, compõe o momento de seu aperfeiçoamento, e a única obrigação essencial dele decorrente, é a que incumbe ao accipiens de restituir a coisa ao tradens. 
No entanto, juristas como Messineo, por exemplo, abominam conclusões como esta e ajuntam que tal situação aplica-se também aos contratos consensuais. Assim, no contrato de locação, segundo este ponto de vista, caso não houvesse a entrega, não se constituiria a obrigação de restituir. Ao que parece, este raciocínio científico quer caminhar à conclusão de que tanto os contratos reais quoad constitutionem quanto os contratos reais quoad effectum estão igualmente revestidos da realidade decorrente da traditio, isto é, a efetiva entrega da coisa.

Por outro lado, importante segmento doutrinário brasileiro, liderado por juristas de escola como Caio Mário da Silva Pereira e Orlando Gomes, defende a dispensa da distinção entre contratos reais e consensuais, entendendo que a diferenciação não anula o princípio do consensualismo, de tal sorte que todos ós contratos se formariam do mesmo modo: pela convergência das vontades. Se do tipo real o contrato, a ausência da entrega implicaria tão apenas no não nascimento. da obrigação de restituir, ou seja, dele, contrato, seria suprimido exclusivamente este efeito, sem o comprometimento da existência mesma da espécie contratual em tela.

Mas, o que sucederia se, na intenção de se formar um contrato real, e depois de integradas as duas vontades, não ocorresse a tradição da coisa? Teria mesmo se constituído, ainda assim, um contrato real? Ou esta convenção teria criado um contrato diverso, inominado? Ou, ainda, quem sabe, teria surgido tão apenas um pré-contrato, preliminar do entabulamento do contrato real pretendido?

Em resposta a tais indagações, encontra-se uma posição quase unânime que revela a natureza jurídica da formulação jurídica havida naquela circunstância, revelando-a como um pré-contrato.

A maior crítica que se faz a esta posição é a seguinte: ainda que se admitisse a conversão do contrato pretendido (real) em pré-contrato (consensual), saber-se-ia que este último, desta maneira integrado nos planos de existência e eficácia dos atos, geraria, como único efeito, o de vincular as partes pré-contratantes à celebração do contrato real principal. Jamais à entrega da coisa.

Ora, o círculo é vicioso.

Por outro lado, atente-se para outro problema derivado da posição dos que entendem que, por força do princípio do consensualismo, o vínculo contratual se estabeleceria simplesmente após o encontro e acordo de vontades. Formando assim o contrato, perderia ele não apenas o seu caráter de real, - já que a entrega da coisa passaria a ser a execução do contrato -, mas também perderia a sua característica de unilateral. Sequer, parece, se poderia falar em bilateral imperfeito pois que, nestas condições, ele teria já toda a caracterização de contrato bilateral ou sinalagmático.

Sob tais considerações e críticas, é de se concluir que o desmesurado esforço intelectual dispendido pelas mais respeitadas e brilhantes capacidades do mundo jurídico revela-se como, talvez, inútil. Não parece emprestar, afinal, qualquer razão suficiente e bastante para se eliminar a distinção legal e doutrinária existente entre contratos reais e contratos consensuais.

Quer nos parecer, afinal, que, quando, por faltar a traditio, não se completar a facti species do contrato real, nada mesmo terá acontecido no mundo contratual, apesar da emissão de duas vontades que se acoplaram. Não houve o perfazimento do tipo contratual, não houve, pois, a produção de qualquer efeito. 


\section{Referências Bibliográficas}

ALVES, Carlos Moreira. Direito romano. 3.ed. Rio de Janeiro, Forense, 1980. v.2. ASCENÇÃO, José de Oliveira. Contrato real. In : ENCICLOPÉDIA Saraiva do Direito. São Paulo : Saraiva, 1977. v.20, p.92-6.

AZEVEDO, Álvaro Villaça. Direito privado : casos e pareceres. Belém : Ed. CEJUP, 1988. v.2

CORREIA, Alexandre; SCIASCIA, Gaetano. Manual de direito romano. 6.ed. São Paulo : Ed. Revista dos Tribunais, 1988.

COVELLO, Sérgio Carlos. Depósito bancário. In : ENCICLOPÉDIA Saraiva do Direito. São Paulo : Saraiva, 1977. v. 23, p.390-4.

FRANÇA, Rubens Limongi. Instituiçōes de direito civil. São Paulo : Saraiva, 1988. GOMES, Orlando. Contratos. 8.ed. Rio de Janeiro : Forense, 1981.

MARKY, Thomas. Contrato (Direito Romano). In ENCICLOPPÉLIA Saraiva do Direito. São Paulo : Saraiva, 1977. v.19, p.146-54.

MONTEIRO, Washington Barros. Curso de direito civil : direito das obrigações 13.ed. São Paulo : Saraiva, 1977. 2.pte.

PEREIRA, Caio Mário Silva. Instituiçōes de direito civil. 2.ed. Rio de Janeiro : Forense, 1975.

WALD, Arnoldo. Obrigaçōes e contratos. 7.ed. São Paulo : Ed. Revista dos Tribunais, 1987. 